\title{
Graduate Student Reflections on Mentorship in a Training and Outreach Program for Families of Children with Autism Spectrum Disorder
}

\author{
Bridget Wright \\ Ohio University, bg656513@ohio.edu \\ Kara Kuykendall \\ kara.kuykendall1@gmail.com \\ Jessica Apsley \\ ja146910@ohio.edu
}

See next page for additional authors DOI: https://doi.org/10.30707/TLCSD3.1Wright

Follow this and additional works at: https://ir.library.illinoisstate.edu/tlcsd

Part of the Scholarship of Teaching and Learning Commons

\section{Recommended Citation}

Wright, Bridget; Kuykendall, Kara; Apsley, Jessica; McCullough, Nicole; Doerbaum, Hannah; Fowler, Megan; Hamm, Heather; Abram, Kristin; Taylor, Sarah O.; McCarthy, John W.; Lee, Chao-Yang; and Benigno, Joann P. (2019) "Graduate Student Reflections on Mentorship in a Training and Outreach Program for Families of Children with Autism Spectrum Disorder," Teaching and Learning in Communication Sciences \& Disorders: Vol. 3: Iss. 1, Article 6.

DOI: https://doi.org/10.30707/TLCSD3.1Wright

Available at: https://ir.library.illinoisstate.edu/tlcsd/vol3/iss1/6

This Student Voices is brought to you for free and open access by ISU ReD: Research and eData. It has been accepted for inclusion in Teaching and Learning in Communication Sciences \& Disorders by an authorized editor of ISU ReD: Research and eData. For more information, please contact ISUReD@ilstu.edu. 


\title{
Graduate Student Reflections on Mentorship in a Training and Outreach Program for Families of Children with Autism Spectrum Disorder
}

\author{
Abstract \\ Undergraduate $(n=19)$ and graduate students $(n=8)$ participated in a two semester training program \\ focused on learning about Autism Spectrum Disorder (ASD) and how to create individualized \\ communication supports for families of children with ASD. The focus of this paper is on the graduate \\ students' training and mentoring experiences. Graduate students' philosophies of mentoring \\ undergraduate students and their final reflections of the experience were analyzed for themes and \\ subthemes. Mentoring philosophies yielded four major themes: role of the mentor, mentoring goals, the \\ mentor-mentee relationship, and learning. Graduate student reflections on their skills gained, what they \\ learned about themselves, their leadership, and the challenges they faced were also categorized into \\ themes. Analyses revealed undergraduate student ratings and qualitative comments regarding graduate \\ student support. Implications and future directions for the development of hands-on training programs \\ allowing graduate students in Communication Sciences and Disorders to assume mentorship roles will be \\ discussed.
}

\section{Keywords}

graduate students, mentorship, outreach, training, autism spectrum disorder

\section{Cover Page Footnote}

Thank you to the OHIO University 1804 Fund awarded to Joann Benigno, John McCarthy, Sarah Taylor and Chao-Yang Lee for supporting the work presented in this manuscript as well as the graduate and undergraduate participants and families who participated in the outreach program.

\section{Authors}

Bridget Wright, Kara Kuykendall, Jessica Apsley, Nicole McCullough, Hannah Doerbaum, Megan Fowler, Heather Hamm, Kristin Abram, Sarah O. Taylor, John W. McCarthy, Chao-Yang Lee, and Joann P. Benigno 


\section{Opening Reflections from Student Authors}

We, the first eight authors of this manuscript, were selected to serve as graduate mentors for a training and community outreach program that would prepare us to better work with children with autism spectrum disorder (ASD) and their families. The program allowed us to not only obtain further knowledge in ASD and increase our confidence in this area, but also to serve as mentors to the undergraduate students who participated in the program. At the outset of our experience, we had a lot of questions such as: What strategies will we use to mentor the undergraduates? What is the right level of help we should provide? Should we tell them exactly what to do or fashion opportunities for them to learn? How does our role fit in the broader context of our faculty mentors' and clinical supervisor's roles? As the year progressed, we learned how to lead, foster the undergraduates' creativity and learning, and refine our personal mentoring styles. In this paper, our experiences in the program are documented with a particular focus on the development and implementation of our mentoring philosophies and our own reflections on the training program. Our "voices" are woven throughout the paper and the major themes of what we gained are summarized.

\section{Overview of Mentorship}

The American Speech-Language-Hearing Association (2017) defines a mentor as "a trusted counselor or guide who also functions as a mentor or coach." According to a mentorship model proposed by Wright-Harp and Cole (2008), peer mentors should be students who have reached a high status in their education, display promising leadership skills, and are willing to act as a mentor to other students in their field. Experiences in mentorship roles allow peer mentors to build and improve upon their existing skills, as well as provide their mentees with knowledge and support to help them be successful (Wright-Harp \& Cole, 2008). Through the present training and outreach program, graduate students in speech-language pathology (SLP) were provided with an opportunity to develop, exercise, and reflect on their mentorship skills during their interactions with undergraduate students. Previous research has provided useful recommendations for graduate student mentors and reported the effective use of peer mentorship in fields outside of Communication Sciences and Disorders (CSD) and in various contexts.

Previous published works written from the perspectives of graduate student mentors offer insight on how to be an effective student mentor. In a student forum publication related to mentorship, graduate students in psychology used their mentoring experiences to provide guiding principles for mentors working with undergraduate students (Evans, Perry, Kras, Gale, \& Campbell, 2009). The student authors suggest that the development of a personal mentorship philosophy, incorporating both available literature on mentorship as well as personal experiences and styles of mentoring, is a beneficial step in the process of becoming a mentor. Notably, students mentioned the importance of having a faculty mentor during the creation of student mentoring philosophies, which was a strategy used in the present study. Also of relevance in the current investigation was the graduate student authors' discussion of the role of mentors in fostering collaboration and being open to the thoughts and opinions of the undergraduate students.

In addition to graduate student researchers, other researchers have offered guidelines for graduate students to keep in mind as they mentor undergraduates. Hopkins (2017) discusses the importance 
of providing undergraduate mentees with intellectual, professional, and social support. With respect to intellectual support, student mentors should provide undergraduates with opportunities to have discussions that promote critical thinking and allow them to share their thoughts and opinions. The provision of professional support involves graduate student mentors helping mentees navigate their future academic endeavors and offering advice based on their own experiences. Graduate student mentors can offer social support to their mentees by doing their best to construct a comfortable and intellectually stimulating environment as well as being open and positive in their interactions with mentees. However, questions remain regarding the effectiveness of graduate student-mentee relationships and, at present, there is minimal empirical evidence related to the effectiveness as well as the bidirectional influence of the graduate student-mentee relationship.

In one study, Conway, Eros, Pellegrino, and West (2010) examined the outcomes of a program focused on fostering interactions between undergraduate and doctoral students in music education. The doctoral students acted as guides to the undergraduates in a variety of situations, such as the classroom, fieldwork, and instrumental performances. Through questionnaires and focus groups, the researchers found that the undergraduate students' perceptions of their interactions with the doctoral students were positive. Undergraduates saw the doctoral students as valuable resources and benefited from hearing about their experiences in the field. Journals kept by the doctoral students throughout the program revealed that the journaling process helped them reflect on their mentorship of the undergraduates. Ideas expressed in doctoral students' journals included finding a balance between sharing their own opinions and allowing undergraduates to come to their own conclusions, as well as understanding the field of music education from the undergraduate perspective. Findings from this program speak to the potential benefits to both undergraduate and graduate students through experiences that provide opportunities for mentorship and interaction.

Graduate student mentorship as a mechanism to promote undergraduate students' interest in research has also been investigated. Kiersma and colleagues (2012) implemented a mentorship program involving graduate and undergraduate students who studied pharmacy. Graduate students were matched with up to three mentees with whom they met at least twice during the semester to talk about research and their future careers. Surveys revealed that both before and after the mentorship experience, graduate students rated professionalism, being open to mentees' thoughts, and helping mentees improve as the most important qualities of a mentor. Additionally, graduate mentors reported high levels of confidence in their mentorship qualities (e.g., organized, patient). Although confidence levels did not differ before and after their mentorship experiences, graduate students expressed that the program positively impacted their perceptions and skills related to communication and mentorship. Advantages of graduate student research mentorship, such as gains in teaching and communication skills, are also reported in other fields including molecular science (Dolan \& Johnson, 2009). Along with the literature on graduate student mentorship of undergraduates in research, research pertaining to student mentorship in the contexts of clinical education and experiences has been conducted.

Within the field of CSD, the benefits of peer mentorship have been examined in the clinical training of graduate students in speech-language pathology. In a study by Kimble and Turner (2017), more experienced graduate students acted as peer mentors to first-year student clinicians. In interviews following the mentorship program, students reported that, overall, the experience 
was beneficial to everyone involved and allowed students to develop clinical skills. While peer mentors did speak of challenges such as finding ways to effectively provide guidance to their mentees, they expressed that overall, they were confident in their mentorship skills. Taken together, research regarding graduate student mentorship shows that these experiences are beneficial to students in both roles and provide graduate students with opportunities to gain skills related to leadership and communication.

\section{The Present Study}

Though student mentorship models have been explored in areas such as music education and pharmacy (Conway et al., 2010; Kiersma et al., 2012) as well as in the clinical training of speechlanguage pathology graduate students (Kimble \& Turner, 2017), there is a lack of research addressing student mentorship in the context of a training and outreach program. To our knowledge, no research exists on graduate student-undergraduate mentoring models within or outside of the field of CSD with a particular focus on community outreach. The current study involved graduate student mentorship of undergraduates in didactic coursework related to ASD and in the context of an outreach program focused on creating communication supports for families of children with ASD (see Benigno, McCarthy, Taylor, Wright, \& Lee., in press), for an in-depth overview of the training program). The research questions of this study included:

1) What are graduate students' philosophies on mentoring undergraduate students?

2) What are graduate students' perceptions of their mentoring experiences during an outreach program for families of children with ASD?

In order to answer these questions, the mentoring philosophies and final reflection papers written by the graduate students were thematically analyzed. Additionally, undergraduate student ratings of graduate student mentor support throughout the program were examined.

\section{Method}

Participants. During the first year of the program, four Master's students in Speech-Language Pathology and eight undergraduate students in CSD participated. The second year included four graduate students, eight undergraduates in CSD, two undergraduates from Music Therapy, and one undergraduate from Psychology. In total, eight graduate students (all female) and 19 undergraduate students (1 male) participated in the training program.

Recruitment and Overview of Training Program. Undergraduate students who participated in the first year of the program were selected by the Principal Investigator (PI; last author) and co-PIs of the award funding the project, due to the timing of the funding awarded. Selection of these undergraduate students was based on academic merit, one reference, statement of interest, resume, relevant experience, and students' ability to commit to the two-semester training experience. During the second year, an application process was used to select students within and outside of CSD. Criteria similar to the first year were used to determine selection. All graduate students were selected based on personal statements and experience reported in their applications to our graduate program. Across the two years of the experience, the PI of the outreach program was the instructor on record for all of the courses. This individual was also responsible for organizing student outreach with all of the families, with additional assistance from the clinical supervisor. Two of the co-PIs also delivered guest lectures related to their areas of expertise and the third co-PI was 
responsible for supporting graduate students' development of a mentoring philosophy. A total of ten families participated in the outreach program and approximately 120 individualized communication supports were created by the undergraduate and graduate students (see Benigno et al., in press).

\section{Procedure.}

Structure of the Training Program. The training program involved two semesters of didactic coursework related to ASD and participation in outreach to families in an underserved area of a Midwestern state who have children with ASD. During the fall semesters, graduate and undergraduate students completed learning activities such as research article presentations and readings in areas related to ASD. Students also learned about the creation and implementation of evidence-based communication supports for individuals with ASD (e.g., visual schedules). A project at the end of the fall semester involved graduate students guiding undergraduates in creating visual supports for a family presented in a case study. Spring semesters included similar learning activities as well as student participation in outreach with families.

Graduate Student Mentoring Roles and Responsibilities. Graduate students had multiple roles throughout the course of the training program. Across both semesters of the program, graduate students held meetings with groups of undergraduates to guide them through discussions of their assigned research papers and provided them with feedback as they created their class presentations of the research. Additionally, pairs of graduate students collaborated to construct and give class lectures pertaining to specific, evidence-based intervention approaches for children with ASD.

During the outreach component of the project, graduate students assisted in conducting the initial assessments with participating children and their families using the Functional Communication Profile-Revised (FCP-R; Kleiman, 2003). Videos of these sessions were used to inform the types of supports and materials to be created for the child. Two graduate students and a group of undergraduates assumed the responsibilities of creating materials for each family. Following the initial assessments, graduate students compiled a list of materials to be created, scheduled and led group meetings, coordinated and supervised workflow for creation of materials, provided feedback on drafts and final products of the materials, and verified that all requested materials were completed. When families returned to receive their materials, graduate students presented each material and provided explanations and specific instructions on how to implement the supports in the home environment.

Along with their responsibilities for didactic and outreach portions of the project, graduate students also constructed their own mentoring philosophy. Graduates completed assigned readings on teaching and mentorship, including selections from What the Best College Teachers Do (Bain, 2004), then met with a faculty mentor associated with this portion of the project. After drafts of philosophies were individually written and peer reviewed, graduate students and the faculty mentor provided feedback on the philosophies during a second meeting. Based on this feedback, the mentoring philosophies were completed and shared with graduate student peers and the faculty mentor during the fall semester. The PI also reviewed and provided feedback; mentoring philosophies were revised and finalized early in the spring semester. In addition to constructing their philosophies on mentorship, graduate students wrote final reflection papers on their experience, which required them to address the skills they had gained, what they learned about 
themselves, their leadership skills, and the challenges they faced in the program. See Table 1 for a summary of student activities and roles across both semesters of the project.

Table 1

Summary of Core Activities for Undergraduate and Graduate Students Across Fall and Spring Semesters

\begin{tabular}{|c|c|c|}
\hline & Fall semester & Spring semester \\
\hline $\begin{array}{l}\text { Undergraduate } \\
\text { students }\end{array}$ & $\begin{array}{l}\text { Weekly reading assignments } \\
\text { Two research article presentations } \\
\text { Readings and workshop sessions on } \\
\text { communication supports } \\
\text { Case study project }\end{array}$ & $\begin{array}{l}\text { Weekly reading assignments } \\
\text { Two research article presentations } \\
\text { Re-evaluation of fall case study } \\
\text { projects } \\
\text { Outreach with families }\end{array}$ \\
\hline $\begin{array}{l}\text { Graduate } \\
\text { students }\end{array}$ & $\begin{array}{l}\text { Weekly reading assignments } \\
\text { FCP-R training and practice } \\
\text { Mentoring UG presentations and } \\
\text { case study project } \\
\text { Group discussion of readings on } \\
\text { teaching and mentorship } \\
\text { Draft of mentoring philosophy }\end{array}$ & $\begin{array}{l}\text { Weekly reading assignments and } \\
\text { lecture on ASD intervention } \\
\text { FCP-R assessments for children } \\
\text { participating in outreach } \\
\text { Mentor UG presentations and UGs' } \\
\text { creation of materials for families } \\
\text { Peer assessment of mentoring } \\
\text { philosophies } \\
\text { Final draft of mentoring philosophy }\end{array}$ \\
\hline
\end{tabular}

Note. $\mathrm{ASD}=$ autism spectrum disorder; FCP-R = Functional Communication Profile- Revised; $\mathrm{UG}=$ undergraduate.

Coding. A trained graduate research assistant who did not participate in the training program analyzed the mentoring philosophies and final papers for core themes following established guidelines in the qualitative literature (e.g., Creswell, 2008). A thematic analysis of the eight graduate students' mentoring philosophies was conducted. The research assistant reviewed each of the mentoring philosophies and created a list of main ideas expressed by the graduate students. These main ideas were grouped into major themes and corresponding subthemes. This process was also used in the analysis of the final reflection papers, yielding major themes in each of the four topic areas addressed. The PI of the project and the first author reviewed and verified the coding of the major themes and subthemes for the mentoring philosophies and final reflection papers. All disagreements were resolved through discussion 


\section{Results}

Results from the qualitative analyses of the mentoring philosophies and final reflection papers are presented first. Major themes and subthemes that emerged from each of the papers are described. Following these results is a summary of undergraduate students' perspectives on graduate student mentorship.

Mentoring Philosophies. In the graduate students' mentoring philosophies, the four major themes included: role of the mentor, the mentor-mentee relationship, mentoring goals, and learning. See Table 2 for a summary of the mentoring philosophy themes and subthemes across all eight graduate mentors.

Table 2

Themes from Mentoring Philosophy Papers

\begin{tabular}{|c|c|c|c|}
\hline Theme & Subtheme & $\begin{array}{c}\text { Frequency of } \\
\text { Response }\end{array}$ & $\begin{array}{c}\text { Unique } \\
\text { Contributors }\end{array}$ \\
\hline \multirow[t]{3}{*}{ Role of the Mentor } & $\begin{array}{c}\text { Mentoring } \\
\text { responsibilities }\end{array}$ & 21 & 6 \\
\hline & $\begin{array}{l}\text { Strategies for } \\
\text { teaching }\end{array}$ & 19 & 7 \\
\hline & $\begin{array}{c}\text { General mentoring } \\
\text { qualities }\end{array}$ & 7 & 4 \\
\hline \multirow[t]{3}{*}{ Mentoring Goals } & $\begin{array}{c}\text { Fostering skills and } \\
\text { personal qualities in } \\
\text { the mentee }\end{array}$ & 12 & 6 \\
\hline & Teaching about ASD & 6 & 4 \\
\hline & $\begin{array}{l}\text { General goals for the } \\
\text { experience }\end{array}$ & 2 & 2 \\
\hline \multirow[t]{3}{*}{$\begin{array}{l}\text { The Mentor-Mentee } \\
\text { Relationship }\end{array}$} & $\begin{array}{l}\text { Reciprocal nature of } \\
\text { the relationship }\end{array}$ & 5 & 5 \\
\hline & $\begin{array}{c}\text { Age comparison } \\
\text { between } \\
\text { mentor/mentee }\end{array}$ & 3 & 3 \\
\hline & $\begin{array}{l}\text { Personal vs. } \\
\text { professional } \\
\text { boundaries }\end{array}$ & 2 & 2 \\
\hline \multirow[t]{2}{*}{ Learning } & Definition of learning & 2 & 2 \\
\hline & Views on learning & 2 & 1 \\
\hline
\end{tabular}

Note. Frequency of Comments refers to the total number of comments in the final reflection papers related to each theme. Unique Contributors refers to the number of different graduate students who made comments related to each theme. 
Role of the Mentor. The most frequent theme that emerged in the graduate students' mentoring philosophies was the role of mentor. With respect to the subtheme of mentoring responsibilities, graduate students expressed the importance of acting as a resource to mentees, providing constructive feedback and support, and encouraging collaboration among group members. One student, for instance, stated that, "I have been beginning to think of a mentor as not only a reference point and guide, but also as a collaborator and supporter." Students expressed the importance of acting as a role model to mentees, particularly through their demonstration of professional behavior and enthusiasm for their subject. In summing up her reflections on her own philosophy, one student noted:

My personal mentoring philosophy is to act as a support to facilitate learning of information and skills that will have an influence on the way that my mentees continue in their academic, personal, and professional endeavors.

Strategies for teaching focused on sharing personal experiences to help mentees learn, making learning experiences meaningful and applicable, and creating a positive, encouraging learning environment. Students also spoke to their belief that mentors have the responsibility of structuring a positive learning environment "that promotes the feeling of excitement and a willingness to learn from one another." Other teaching strategies discussed included using mistakes as teaching opportunities and understanding the strengths of mentees. From the perspective of one student, mentors should "make an effort to draw on the strengths of each individual and acknowledge their differences in a way that will make the process the most beneficial and meaningful for all involved." General mentoring qualities included active listening, being an invested and excited member of the learning environment, maintaining a positive attitude, and encouraging mentees. Within this subtheme, students reflected on how a mentor should "remain an invested, excited, active member of the environment" and be "willing to assist them [mentees] with a positive attitude and encouragement."

Mentoring Goals. The most frequently mentioned subtheme under mentoring goals pertained to fostering skills and personal qualities in the mentee. Here, graduate mentors referred to encouraging mentees to think creatively, critically, and independently. Another subtheme related to mentoring goals was teaching about ASD, which involved mentors seeking to help mentees gain more knowledge in this area, particularly through positive learning experiences. In reference to the third subtheme, one student reflected on her mentoring goals specific to ASD in stating: "My main goal as a mentor is to ignite a passion for learning about autism spectrum disorder and providing services to others that can generalize to experiences and passion outside of the class itself."

The Mentor-Mentee Relationship. Students reflected on the reciprocal nature of the mentormentee relationship, which is one that "is not only beneficial for the mentee, but is a process that is equally enriching and beneficial for the mentors as well." Similarly, one student remarked that she sought to "develop a reciprocal relationship by being receptive to their ideas as well as voicing my own." Exchanging knowledge and learning from one another was a commonly mentioned idea related to reciprocity in the mentor-mentee relationship. An additional aspect of the mentor-mentee relationship that was discussed was the narrow age gap between mentor and mentee. In other words, students commented on how they as mentors were not much older than their undergraduate 
mentees, which made mentoring somewhat of a challenge. The final subtheme in the area of the mentor-mentee relationship was personal versus professional boundaries. Graduate student mentors wrote about the importance of distinguishing between one's roles as a learner and as a mentor. In the words of one student, it is vital to "develop a personable and friendly, yet professional relationship with your mentees."

Learning. The final theme of the mentoring philosophies was learning, which included the following subthemes: definition of learning and views on learning. Graduate students who contributed to this theme shared their definitions of learning, which emphasized the integration and application of one's knowledge. Two students also expressed their views on learning by stating that learning should occur in a "no risk environment" where there is not an abundance of pressure on students to perform well.

Final Reflection Papers. In their final reflections on their participation in the training program, graduate students wrote on their overall experience. Students were asked to address four areas: the skills they gained, what they learned about themselves, their leadership, and the challenges they faced. The main focus of this section concerns the leadership and mentoring skills that graduate students developed in working with the undergraduates in this program, as well as the perceived challenges related to their roles in the training and outreach program. See Table 3 for a summary of the themes within each final reflection topic.

Table 3

Themes from Final Reflection Papers

\begin{tabular}{|l|c|c|c|}
\hline Theme & Subtheme & $\begin{array}{c}\text { Frequency of } \\
\text { Comments }\end{array}$ & $\begin{array}{c}\text { Unique } \\
\text { Contributors }\end{array}$ \\
\hline Skills gained & $\begin{array}{c}\text { Research articles and } \\
\text { presentation skills }\end{array}$ & 6 & 5 \\
\hline & $\begin{array}{c}\text { Creating materials } \\
\text { Familiarity with assessment } \\
\text { protocol }\end{array}$ & 5 & 4 \\
\hline & $\begin{array}{c}\text { Knowledge of ASD } \\
\text { communication skills }\end{array}$ & 5 & 3 \\
\hline & $\begin{array}{c}\text { Mentoring } \\
\text { Interpersonal/ }\end{array}$ & 3 \\
\hline & $\begin{array}{c}\text { Allied professionals } \\
\text { Family/child interaction }\end{array}$ & 2 & 2 \\
\hline & Other skills & 2 & 2 \\
\hline & Self-understanding and & 18 & 3 \\
\hline
\end{tabular}




\begin{tabular}{|c|c|c|c|}
\hline & $\begin{array}{l}\text { Gaining and seeking } \\
\text { knowledge }\end{array}$ & 6 & 5 \\
\hline & Mentoring & 2 & 2 \\
\hline & Families & 2 & 2 \\
\hline \multirow[t]{4}{*}{ Leadership } & Leadership qualities gained & 8 & 6 \\
\hline & $\begin{array}{l}\text { Reflections on mentoring } \\
\text { skills }\end{array}$ & 7 & 4 \\
\hline & $\begin{array}{l}\text { Communication and } \\
\text { feedback }\end{array}$ & 6 & 4 \\
\hline & Positivity & 4 & 4 \\
\hline \multirow[t]{3}{*}{ Challenges } & $\begin{array}{l}\text { Managing the role of a } \\
\text { student mentor }\end{array}$ & 8 & 6 \\
\hline & Scheduling/time commitment & 6 & 6 \\
\hline & Other challenges & 2 & 2 \\
\hline
\end{tabular}

Note. Frequency of comments refers to the total number of comments in the final reflection papers related to each theme. Unique contributors refer to the number of different graduate students who made comments related to each theme.

Skills Gained. The most common skills that graduate students mentioned they had improved upon through the program were related to reading and presenting information from research articles. In the words of one student:

...I have gained experience and knowledge of how to effectively read and comprehend research articles. Repeated exposure to individually reading research articles, combined with presentations and conversations discussing the research articles in class, has solidified my ability to not only read information but retain it. As a future health professional who will be implementing evidence-based practice this will be an invaluable skill.

Another student discussed how refined abilities in the area of finding credible research will be important as a future SLP, regardless of the work setting. Graduate students also commonly spoke to how they were able to build skills related to their knowledge and ability to create and implement evidence-based communication supports for individuals with ASD (e.g., Social Stories ${ }^{\mathrm{TM}}$, visual schedules). They also appreciated the opportunity to learn about tools that are commonly utilized in the assessment of individuals with ASD, such as the FCP-R (Kleiman, 2003). Students frequently commented on how through their participation in the program, their knowledge of ASD, interpersonal and communication skills, mentoring skills, and knowledge of other professions had developed.

Self. In writing about what they learned about themselves through their mentoring experience, students expressed newfound self-understanding and insight. Specifically, some students had a better idea of the populations they wanted to work with as future SLPs (e.g., individuals with ASD, families of individuals with dementia). Students also referred to discovering their personal 
interests, strengths, and weaknesses during their roles as mentors in the training and outreach program. Under the subtheme of gaining and seeking knowledge, students shared how they learned to feel comfortable asking questions and seeking assistance from others. The subject of mentorship came up as students described their self-growth through statements such as, "the skill of mentoring is of great value to me." Lastly, two graduate mentors voiced in this section that they "truly... enjoy[ed] providing resources for families in the community and valued the needs of the families they served.

Leadership. In the leadership section of the papers, students frequently spoke to the specific leadership skills and qualities they gained. In particular, students reflected on their improved abilities in planning and problem solving. Flexibility and confidence in their roles and abilities were among the leadership qualities mentioned, as well. One student captured the subtheme of leadership qualities gained with the following quote:

I feel that this experience tested my developing leadership skills and sharpened them throughout the process. As challenges arise, it is the leaders who must discover solutions, be a consistent role model, and keep the unity within the group.

Additionally, students referred to their mentoring philosophies and mentorship roles while discussing the ways in which their leadership developed from the program. When reflecting on the development of her mentoring philosophy, one student spoke to how she was able to "utilize it as a guide" throughout the course of the program. This particular student also expressed that her experiences as a graduate student mentor helped her become confident in her mentorship skills, which will be valuable in her future professional experiences in supervising graduate student clinicians. Students also reflected on how skills related to communication and distribution of feedback to the undergraduates were important aspects of their leadership. Strategies valued in this area were clear communication and the use of constructive feedback.

Challenges. The challenges discussed by the graduate students concerned either difficulties in their mentorship role or scheduling and time conflicts. A challenge that was noted by multiple students had to do with navigating their roles as mentors to the undergraduates, particularly in terms of the amount of assistance to provide their mentees when they had questions about concepts, assignments, or projects. Student mentors expressed that determining a balance between simply giving mentees the answers they were looking for versus not providing them with enough information to answer their own questions was a common challenge. In the words of one graduate student:

Knowing how much guidance to give the undergraduates without giving them a concrete answer or not giving them enough help was difficult for me. I was concerned that not answering their question fully would confuse them, but I was also hesitant to give them too much information or help. I found that I naturally learned how to overcome this challenge, as I became more confident in my role as a leader. 
Graduate students also found it difficult to coordinate times to meet with other graduate students and undergraduate students in order to complete assignments and materials for families. Similarly, balancing other responsibilities with their participation in the program was mentioned as a challenge. In instances where time and scheduling were mentioned as challenges, students often reflected on the ways in which they combated these difficulties (e.g., meeting in smaller groups to complete tasks).

Undergraduates' Perspectives of Mentors. At the end of each semester, undergraduates had the opportunity to rate the support provided by the graduate student mentors for all of the activities in the course on a scale of 1-5 $(1=$ not supportive at all; $5=$ strong support $)$. Across both cohorts, undergraduates' ratings of their mentors across all core course activities were quite positive $(M=$ $4.37-4.79$ ). See Table 4 for a summary of undergraduate ratings of graduate student support. In their survey comments, undergraduates expressed appreciation for constructive feedback and suggestions provided by the graduate students. Although one student felt that the mentors provided too much assistance, an overwhelming majority of students were satisfied with the support they received; comments made by students referred to how their mentors were "always offering support but they have let us really be in control" and how they "helped us, but mainly by giving us the tools we needed to succeed independently." Additionally, undergraduates commonly mentioned how the graduate student mentors were willing to help and make themselves available to provide support.

Table 4

Undergraduate Ratings of Graduate Student Mentors' Support for Course Activities

\begin{tabular}{|l|c|}
\hline \multicolumn{1}{|c|}{ Activity } & $\boldsymbol{M}$ (SD) \\
\hline $\begin{array}{l}\text { Presentations } \\
\text { Fall research article } \\
\text { presentations }\end{array}$ & $4.63(.86)$ \\
$\quad \begin{array}{l}\text { Spring research article } \\
\text { presentations }\end{array}$ & $4.37(.68)$ \\
Fall case study project & $4.79(.53)$ \\
Working with families & $4.74(.45)$ \\
\hline
\end{tabular}

Note. Ratings measured on a scale of 1-5. $1=$ not supportive at all; $5=$ strong support.

\section{Discussion}

Through their participation in a training and outreach program that provided individualized, evidence-based communication supports to families of children with ASD, graduate students had the opportunity to act as mentors to undergraduate students, as well as develop their own skills related to leadership, research, and communication. Themes of students' personal mentoring philosophies reflected their values as a mentor, such as being enthusiastic facilitators of learning, providing mentees with appropriate support, and maintaining a professional and reciprocal relationship with mentees. When reflecting on their participation in the program, graduate students discussed their personal gains in areas related to research, communication, assessment, and 
creation of materials. Although they experienced challenges in their roles as mentors, students felt that they were able to exercise their leadership skills and strategies throughout the program. Overall, based on thematic analysis of students' mentoring philosophies and reflections on their experiences as well as undergraduate ratings of their support, the current training and outreach model was successful in increasing student knowledge about ASD and evidence-based communication supports, as well as providing a context for the development of skills related to mentorship, leadership, and communication.

The benefits and challenges of mentorship expressed by the graduate students in this training and outreach program align with those reported in by student mentors in previous research in CSD and other related fields (Conway et al., 2010; Dolan \& Johnson, 2009; Kimble \& Turner, 2017). Additionally, students in the present study reflected on their personal mentorship values in their mentoring philosophies (e.g., recognizing individual strengths of mentees), which were similar to the mentorship qualities expressed by graduate student mentors in the field of pharmacy (Kiersma et al., 2012). These commonalities across fields of study and mentorship contexts speak to the universal benefits and challenges of student mentorship and show that student mentors have similar ideas of what it means to be an effective mentor.

Through their experiences interacting and collaborating with undergraduates, graduate students are able to continue developing and strengthening their mentorship skills (Kiersma et al., 2012), all while reflecting on qualities they believe are important for a mentor to possess. For instance, graduate students believed that mentors should act at role models and guides, which Gee and Popper (2017) also expressed as being vital roles of mentors. The findings of the current study, along with the findings of Kiersma et al. (2012), present the perceptions of graduate students on the qualities of an effective mentor: acting as source of support for mentees, being open to the thoughts and experiences of others, and acting professionally. Notably, graduate students in the present study and peer mentors in the clinical peer mentorship study by Kimble and Turner (2017) both expressed that finding ways to appropriately and accurately guide their mentees was a source of struggle as a student mentor. By proving graduate students with opportunities to act as mentors to other students with the help of faculty and clinical supervisors, these students are able to construct their beliefs on what it means to be a mentor and practice these strategies in a safe and supportive environment. Such experiences will be beneficial to students as future professionals, as they will likely play a role in training students who are entering the field (Turner, Duesing, Kemper, Kimble, \& Turner, 2009).

\section{Future Directions and Implications for Training Students}

Extensions of this work include expanding the content and scope of this type of program and further developing academic and clinical opportunities for graduate students to mentor undergraduates in our field. Similar models of mentorship could include clinical populations other than ASD and provide different forms of community outreach (e.g., providing support to caregivers of individuals with dementia). Additionally, opportunities for graduate students to mentor undergraduates in a clinical setting in addition to the classroom setting could be worked into future mentorship programs. For instance, undergraduate students could observe and assist graduate students and faculty mentors during interactions with clients and their families. 
Future directions could also be the incorporation of interdisciplinary collaboration in programs involving graduate student mentorship. Participation of graduate students from related fields (e.g., music therapy and physical therapy) could provide students with further experience in working as part of an interprofessional team, which will be beneficial to their future careers as healthcare professionals. Such experiences could also provide undergraduate and graduate students with research experiences in the areas of mentorship and outreach. Overall, training programs that involve graduate student mentorship have the potential to foster the development of more wellrounded professionals with a deeper appreciation and affinity for communication and collaboration in their future careers.

Unfortunately, there is minimal published evidence on the role of graduate students in mentoring undergraduates. Given the paucity of work in this area, this manuscript represents a first step in documenting the voices of graduate students who had the opportunity to serve as mentors in the context of an outreach program. We do not believe that a lack of published evidence is representative or indicative of the state of our field or health professions more broadly - activities similar to these are likely occurring at other institutions. However, as journals such as Teaching and Learning in Communication Sciences \& Disorders are established across the health professions, it is our hope that these types of training experiences are documented and disseminated.

\section{Conclusion from Student Authors}

We are grateful to have the opportunity to share our philosophies of mentorship, as well as the knowledge and experience we gained through our roles as graduate student mentors. As beginning clinicians, we have seen the skills we have gained through this program reflected in our practice on a daily basis. Although we will continue to develop and refine our mentoring and leadership skills throughout our careers, we would like to offer advice to current and prospective graduate student mentors. A compilation of recommendations from each student author can be found in the appendix. It is our hope that graduate students will embrace the opportunity to act as mentors to undergraduate students and that our advice will be helpful as students embark on their mentorship journeys.

\section{References}

American Speech-Language-Hearing Association. (2017). Mentorship in communication sciences and disorders. Retrieved from http://www.asha.org/Academic/mentorship/

Bain, K. (2004). What the best college teachers do. Cambridge, MA: Harvard University Press.

Benigno, J. P., McCarthy, J. W., Taylor, S. O., Wright, B. M., \& Lee, C. (in press). Training students through a community outreach program to support families of children with autism spectrum disorder. Teaching and Learning in Communication Sciences and Disorders.

Conway, C., Eros, J., Pellegrino, K., \& West, C. (2010). The role of graduate and undergraduate interactions in the development of preservice music teachers and music teacher educators: A self-study in music teacher education. Bulletin of the Council for Research in Music Education, 183, 49-64.

Creswell, J. W. (2008). Educational research: Planning, conducting, and evaluating 
quantitative and qualitative research (3rd ed.). Upper Saddle River, NJ: Pearson Education, Inc.

Dolan, E., \& Johnson, D. (2009). Toward a holistic view of undergraduate research experiences: An exploratory study of impact on graduate/postdoctoral mentors. Journal of Science Education and Technology, 18, 487-500. doi: 10.1007/s10956-009-9165-3

Evans, S. E., Perry, A. R., Kras, A., Gale, E. B., \& Campbell, C. (2009). Supervising and mentoring undergraduates: A graduate student perspective. The Behavior Therapist, 32, 77-82.

Gee, K. L. \& Popper, A. N. (2017). Improving academic mentoring relationships and environments. Acoustics Today, 13, 27-35.

Hopkins, P. D. (2017). Tips and tools for mentoring undergraduates as a graduate student. Retrieved from https://www.psychologicalscience.org/observer/tips-and-tools-formentoring-undergraduates-as-a-graduate-student\#.WWOH14Tyu70

Kiersma, M. E., Hagemeier, N., Chen, A. M. H., Melton, B., Noureldin, M., \& Plake, K. S. (2012). A graduate student mentoring program to develop interest in research. American Journal of Pharmaceutical Education, 76, 1-9. doi: 10.5688/ajpe766104

Kimble, C., \& Turner, G. (2017). Student peer mentoring in the clinical training of speechlanguage pathologists. SIG 11 Perspectives on Administration and Supervision, 22, 12-27. doi: $10.1044 /$ aas 22.1 .12

Kleiman, L. I. (2003). Functional communication profile revised. Austin, TX: PRO-ED, Inc.

Turner, G., Duesing, B., Kemper, T., Kimble, C., \& Turner, J. (2009, November). Student peer mentoring in clinical training of speech-language pathologists. Presentation at the meeting of the American Speech-Language-Hearing Association, New Orleans, LA.

Wright-Harp, W., \& Cole, P. A. (2008). A mentoring model for enhancing success in graduate education. Contemporary Issues in Communication Science and Disorders, 35(1), 4-16. 


\section{Appendix}

Student Author Recommendations to Graduate Student Mentors

1. Always try to keep the lines of communication open.

2. Be personal and responsive to students' questions and concerns, but do not allow them to rely on you too much or too often.

3. Remember that is important to be supportive of your mentees and act as a resource. At the same time, it is important to remember that the best way to learn is by doing, and sometimes by failing. Step back and see how mentees handle situations. By doing this, mentees are able to learn and grow; you may learn a thing or two in the process, as well!

4. Support your mentees' creativity by guiding and supporting them with your knowledge, but not limiting them to a narrow point of view on the topic.

5. Make an effort to really get to know the students you are mentoring. Know what their interests are, their areas of strength, and areas they wish to improve upon. This will not only allow you to better serve them as a mentor, but will also build rapport and make the experience more personal.

6. Set clear goals and boundaries so that you are able to successfully balance all of the aspects of your position and understand your role as a peer mentor.

7. Allow your mentees to learn from you and allow yourself to learn from them! Be open to the idea that you will not only teach and guide your mentees, but you will also learn from them. The most powerful part of the mentoring experience is the shared learning from both parties to meet a common goal.

8. Be prepared for the knowledge that community brings. Be willing to teach and to learn from those you are mentoring. When minds gather around an idea, the possibilities are limitless!

9. Take the time up front to deeply consider what being a mentor means to you. It is important that you understand what your goals are for yourself and your mentee, as well as the relationship that you are building with them.

10. Reflect on who was a good mentor for you as a learner and what qualities you admired in that individual. Think about what your mentor was like and what qualities/skills you want to continue using and what you may adjust to fit your own philosophy. Think about both positive and negative experiences as a learner so you can take those and use them in your own mentoring philosophy. 